\title{
ЛЮМИНЕСЦЕНЦИЯ КВАРЦ-ХАЛЦЕДОНОВЫХ ОБРАЗОВАНИЙ КУЗБАССА И ЕЁ СВЯЗЬ С ГЕОХИМИЧЕСКИМИ ОСОБЕННОСТЯМИ АГАТОВОЙ МИНЕРАЛИЗАЦИИ
}

\author{
Борозновская Нина Николаевна', \\ boroznovskaya@mail.ru
}

\section{Звягинцева Елизавета Владимировна1, zmei7772006@mail.ru}

\author{
Корнева Александра Павловна ${ }^{1}$, \\ korneva@mail.tsu.ru
}

\author{
Небера Татьяна Степановна ${ }^{1}$, \\ tsnebera@mail.ru \\ 1 Томский государственный университет,
Россия, 634050, г. Томск, пр. Ленина, 36.
}

\begin{abstract}
Актуальность. Квари-халцедоновые образования Кузбасса являются потенциально ювелирно-поделочным материалом, при этом степень их минералогической изученности недостаточна. Кроме того, требуют дальнейшего изучения некоторые аспекты формирования агатов.

Цель: изучение люминесцентных характеристик квари-халцедоновых образований в пределах проявлений Южно-Кузбасского магматического ареала, их изменений по зонам в исследуемых образцах, вариаций в поведении отдельных центров свечения, связанных с собственными и примесными дефректами, выяснение возможного влияния геохимических особенностей исследуемых минералов на их люминесцентные свойства.

Объекты: квари-халиедоновые образования с проявлений Южно-Кузбасского магматического ареала (проявление россыпного типа у д. Ключи (Крапивинский район), миндалекаменные базальты с агатовой минерализацией проявления участка Терсюк (Новокузнецкий район), миндалекаменные базальты с агатовой минерализацией проявлений Салтымаковского хребта (Крапивинский район).

Методы: рентгеноструктурный анализ, рентгенолюминесцентный анализ, масс-спектрометрия с индуктивно связанной плазмой.

Результаты. Методом рентгеноструктурного анализа изучен минеральный состав. Главным образом представлены квари и халиедон, при этом наибольшее содержание халиедона наблюдается в миндалинах с концентрически-зональным строением. В числе других минералов встречаются кристобалит, доломит, кальцит, цеолиты. Посредством проведения рентгенолюминесиентного анализа получены данные о содержании собственных и примесных дефректов различной природы. Распределение центров люминесценции в слоях агата проявления Терсюк может свидетельствовать о смене окислительного потенциала (во внешней зоне) на восстановительный (во внутренних зонах), что подтверждается геохимическими данными. Для оникса Салтымаковского хребта характерна идентичность спектров РЛ для всех исследуемых слоев, что свидетельствует о постоянстве условий минералообразования. В целом сделан вывод о преобладании в миндалинах участка Терсюк восстановительной среды, а в миндалинах проявлений Салтымаковского хребта и у д. Ключи - окислительной.
\end{abstract}

\section{Ключевые слова:}

Квари, халцедон, агат, оникс, Южно-Кузбасский магматический ареал, люминесценция, структурные дефекты.

\section{Введение}

Кварц-халцедоновые образования Кузбасса являются потенциально ювелирно-поделочным материалом, при этом степень их минералогической изученности недостаточна. Кроме того, требуют дальнейшего изучения некоторые аспекты формирования агатов $[1,2]$. Нами на территории Кузбасса ранее были выделены два генетических типа подобных образований: жильный и миндалевидный [3]. По структурнотекстурному признаку среди последних отмечены три группы агатовых образований: с концентрическизональным строением миндалины (собственно агаты), с ониксовым рисунком и комбинированного типа. Кроме того, анализировался их микропримесный состав [4]. Таким образом, ранее были получены данные о структурно-текстурных и геохимических характеристиках исследуемых образцов.
Цель предлагаемой работы - исследование люминесцентных характеристик кварц-халцедоновых образований проявлений Кузбасса и выяснение возможного влияния геохимических особенностей исследуемых минералов на их люминесцентные свойства. Важно проследить, как меняется люминесценция по зонам в каждом из исследуемых образцов, отметить существенные вариации в поведении отдельных центров свечения, связанных с примесными и собственными дефектами, выявить связь люминесцентных свойств с геохимическими особенностями. Анализ полученных данных может дать важную информацию относительно генетических аспектов процесса формирования агатов.

\section{Объект исследования}

Образцы для исследований были отобраны на территории Кузнецкого бассейна с трёх участков с ага- 
товой минерализацией (рис. 1). Участок Терсюк, проявления Салтымаковского хребта и проявление россыпного типа у деревни Ключи расположены на территории Новокузнецкого и Крапивинского районов. Агатовая минерализация этой зоны связана с миндалекаменными разностями раннемезозойских базальтов «мелафировой подковы», локализованной в Бунгарапской мульде среди нижнетриасовых терригенных отложений. «Мелафировая подкова» дугообразно выражается в виде Салтымаковского, Ажендаровского, Караканского хребтов, Кайлотских гор, Тарадановского увала, Осташкиного камня и входит в состав Южно-Кузбасского магматического ареала. Более подробное геологическое описание этих объектов приводится в предшествующих работах $[3,4]$.

\section{Методика исследования}

Отобранные образцы были проанализированы методами рентгеноструктурного анализа (РСА), рентгенолюминесцентного анализа (РЛ) и массспектрометрии с индуктивно связанной плазмой (ICPMS). Рентгенограммы получены с помощью дифрак- тометра PANalytical X'Pert PRO [4]. Спектры РЛ снимались с помощью установки, собранной на базе монохроматора МДР-12 с компьютерным управлением, по методике, описанной ранее [5]. Построение спектров проводилось в диапазоне длин волн 200-800 нм. Источником возбуждения служила рентгеновская трубка БСВ-2 от аппарата УРС-55 с Мо-антикатодом. Данные по микроэлементному составу получены на квадрупольном ICP-MS спектрометре Agilent 7500 (аналитик - Е.С. Рабцевич).

Для детального исследования данными прецизионными методами было отобрано с каждого проявления по 1-2 образца, которые были распилены по слоям с получением суммарно 25 проб. Распиловка производилась с помощью высококачественных алмазных дисков с непрерывной подачей воды на диск. Для применения всех методов анализа использовались порошковые пробы, истёртые в корундовой ступке [4]. Благодаря распилу образцов на отдельные слои удалось получить послойные характеристики кварцхалцедоновых образований.

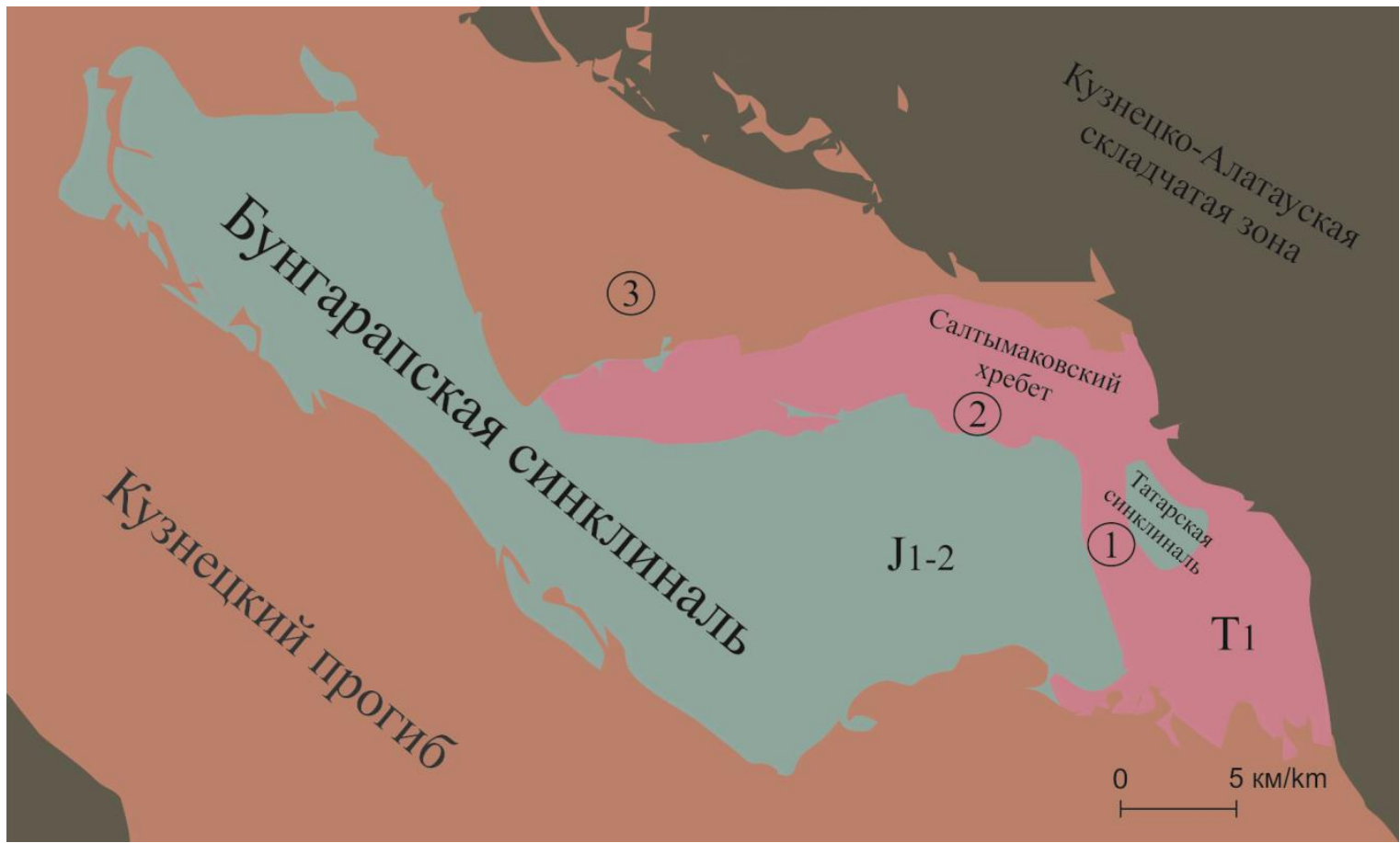

Рис. 1. Локализачия проявлений агатовой минерализачии на территории Кузнецкого бассейна: 1 - участок Терсюк, 2 - проявление Салтымаковского хребта, 3 - проявление у д. Ключи

Fig. 1. Allocation of occurrences of agates within Kuznetsk basin: 1 - Tersyuk occurence, 2 - Saltymakovskiy ridge occurrence, 3 - Klyuchi occurrence

\section{Результаты и обсуждение}

По результатам рентгеностуктурного анализа минеральный состав исследуемых образцов в основном сводится к наличию кварца и халцедона, часто с преимущественно кварцевым составом, что является одной из особенностей данных образований (рис. 2). В оторочках миндалин встречаются кристобалит, доломит, кальцит, цеолиты. Для диагностики минералов кремнезёма использована методика, применяющая различия в соотношениях интенсивностей рефлексов 110 (2.45 $\AA), 102$

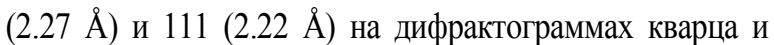
халцедона [6]. Наибольшее содержание халцедона наблюдается в миндалинах с концентрическизональным строением. В числе других минералов встречаются кристобалит, доломит, кальцит, цеолиты.

Полученные спектры РЛ представлены полосами излучения в диапазонах (нм): 280-300, 320-350, 390400, 420-450, 540-590, 620-700. Перечисленные полосы РЛ в основном связаны с собственными дефектами различных типов (таблица). 
A

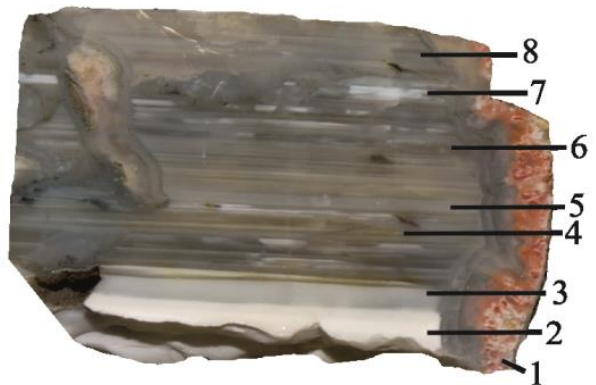

1 - кристобалит-кварц-цеолит; 2, 3 - кварц; 4-8 - кварц-халцедон

B

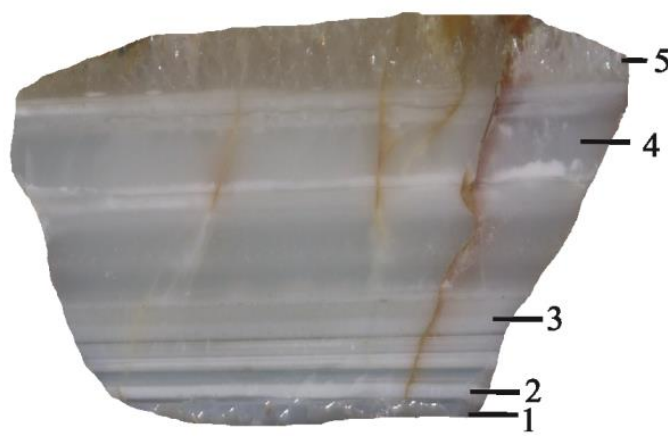

1-5 кварц b

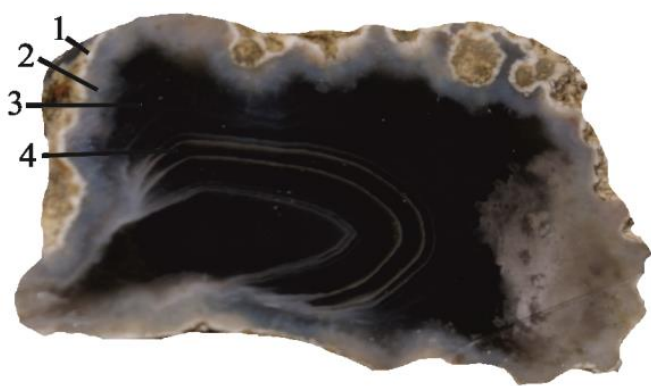

1 - кристобалит-кварц; 2-4 - кварц-халцедон

$\Gamma$

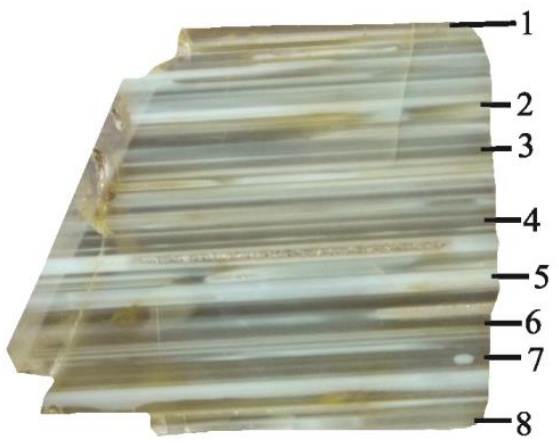

1, 2, 5, 7, 8 - халцедон; 4 - кварц;

3, 6 - кварц-халцедон

Pис. 2. Послойный минеральный состав квари-халцедоновых образований проявления Терсюк (А, Б), Салтылмаковского хребта (B), проявления у д. Ключи (Г)

Fig. 2. Mineral composition of different layers of quartz-chalcedony formations from Tersyuk (A, B), Saltymakovskiy ridge (C) and Klyuchi (D) occurrences

Полоса РЛ в диапазоне 280-300 нм связана с присутствием вакансии кислорода. Согласно мнению некоторых авторов, содержание вакансий кислорода и кремния в агатах ощутимо выше, чем в кристаллическом кварце [7]. И все же наиболее интенсивно эта полоса проявлена в кварце верхних частей миндалин и полостей, что свидетельствует о дефиците кислорода в минералообразующей среде к концу процесса агатообразования (рис. 3). РЛ при 300-470 нм может быть связана как с собственными дефектами, так и с микропримесями $\mathrm{Al}, \mathrm{Li}$ и Na. Существует корреляция между содержаниями $\mathrm{Al}$ и $\mathrm{Li}$ и интенсивностью полосы 330-340 нм, что свидетельствует в пользу того, что центры типа $\mathrm{AlO}_{4}{ }^{4} / \mathrm{Li}^{+}$могут также выступать как активаторы свечения в ультрафиолетовой области спектра [8]. Полоса с максимумом свечения около 450 нм возникает вследствие рекомбинации самозахваченных экситонов [9]. Широкая полоса в диапазоне 560-580 нм была обнаружена при проведении люминесцентного анализа природного гидротермального кварца и связана с вакансиями кислорода [10]. По мнению ряда авторов, её присутствие может отличать спектры люминесценции кварца от спектров люминесценции халцедона [11]. Оранжево-красное свечение на 620-650 нм было зарегистрировано у многих образцов синтетического и природного кварца с наибольшей интенсивностью в гидротермальном и скрытокристаллическом [12].
Таблица. Краткая характеристика возможных центров люминесценции в квари-халцедоновых образованиях

Table. $\quad$ Possible luminescence centers in quartz-chalcedony formations

\begin{tabular}{|c|c|}
\hline $\begin{array}{l}\text { Длина волны при } \\
\text { максимальной } \\
\text { интенсивности, нм } \\
\text { Maximum intensity } \\
\text { wavelength, nm } \\
\end{array}$ & $\begin{array}{c}\text { Характеристика центра люминесцен- } \\
\text { ции } \\
\text { Luminescence centers }\end{array}$ \\
\hline $\begin{array}{l}280-290 \\
310-330 \\
560-580\end{array}$ & $\begin{array}{c}\text { Вакансия кислорода }[13,10] \\
\text { Oxygen vacancy }[13,10]\end{array}$ \\
\hline $\begin{array}{l}330-360 \\
400-440\end{array}$ & $\mathrm{AlO}_{4}{ }^{4} / \mathrm{Na}^{+}, \mathrm{Li}^{+}[8]$ \\
\hline $\begin{array}{l}370-400 \\
450-470\end{array}$ & $\begin{array}{c}\text { Междоузельный кислород, дефекты } \\
\text { матрицы } \mathrm{SiO}_{2}[5,9,14] \\
\text { Interstitial oxygen, } \mathrm{SiO}_{2} \text { matrix defects } \\
{[5,9,14]}\end{array}$ \\
\hline $620-650$ & $\begin{array}{c}\text { Дырочные центры, связанные с немо- } \\
\text { стиковым кислородом и силанольны- } \\
\text { ми группами [13, } 15] \\
\text { Nonbridging oxygen and silanol group } \\
\text { hole centers }[13,15]\end{array}$ \\
\hline $670-740$ & $\mathrm{Fe}^{3+}[14,16,17]$ \\
\hline
\end{tabular}

В длинноволновой области могут быть выделены по меньшей мере две накладывающиеся друг на друга полосы - 620 и 650 нм. Появление полосы 620 нм связано с немостиковым кислородом с предшественниками в виде немостиковых гидроксильных групп $(: \mathrm{Si} \pm \mathrm{OH})$ [18]. Излучение при 650 нм многие исследо- 
ватели также приписывают немостиковому кислороду $\equiv \mathrm{Si}-\mathrm{O} \bullet$, т. е. атому кислорода с одной разорванной связью. Возникновение немостикового кислорода проявляется особенно активно при наличии групп $\mathrm{OH}^{-}$в структуре минерала [15]. Силанольные группы, представляющие собой гидроксильную группу, связанную с атомом кремния, являются наиболее благоприятными предтечами образования немостикового кислорода $[19,20]$. Излучение в этой части спектра особенно характерно для халцедона [11]. Предполагается, что красное свечение на границе с инфракрасной областью (около 705 нм) может быть следствием замещения кремния либо алюминия на $\mathrm{Fe}^{3+}$ по аналогии с другими силикатами $[14,16,17]$. С другой стороны, на наш взгляд, и в этой спектральной области возможно участие собственных дефектов на базе силанольных групп. Необходимо проследить послойное изменение люминесцентных характеристик.

Для спектров РЛ агата и оникса участка Терсюк характерно проявление вакансий кислорода (280-325, 560-580 нм), что свидетельствует о недостатке кислорода. Это характерно для всех внутренних слоев, представленных в данном случае халцедоном (рис. 4). В кристобалите внешней зоны подобные центры не проявляют себя. В отличие от внутренних зон, в спектре внешней зоны присутствуют полосы излучения в спектральном диапазоне 400-500 нм, за которые могут быть ответственны дефекты матрицы $\mathrm{SiO}_{2}$, междоузельный кислород, дефекты типа $\mathrm{SiO}_{4}{ }^{3-} / \mathrm{Na}^{+}$, $\mathrm{AlO}_{4}{ }^{4-} / \mathrm{Na}^{+}, \mathrm{AlO}_{4}{ }^{4-} / \mathrm{Li}^{+}$. Подобное распределение дефектов в пространстве может свидетельствовать о смене окислительного потенциала (во внешней зоне) на восстановительный (во внутренних зонах). Но и во внутренних зонах иногда наблюдается влияние колебаний окислительно-восстановительного режима. Так, в слоях 22-4 и 22-5 исчезают полосы излучения в красном диапазоне, за которые могут быть ответственны ионы $\mathrm{Fe}^{3+}$, что свидетельствует об усилении восстановительного потенциала.

Это подтверждается геохимическими данными, полученными ранее (рис. 5). Для образца 22 характерна положительная европиевая аномалия для всех слоев $\left(\mathrm{Eu} / \mathrm{Eu}^{*}=1-2,4\right)$, что свидетельствует в пользу восстановительной обстановки, поскольку сквозь поры свободнее проникает $\mathrm{Eu}^{2+}[21]$. Для образца 25 в первом и четвертом слоях отмечена положительная аномалия $\left(\mathrm{Eu} / \mathrm{Eu}^{*}=3-9,8\right)$, в то время как во втором и третьем слоях - отрицательная $\left(\mathrm{Eu} / \mathrm{Eu}^{*}=0,5-0,9\right)$. Все это может быть связано с колебаниями окислительновосстановительного режима. Рост концентраций европия к центру может указывать на смену окислительной обстановки на восстановительную, которая способствовала повышению мобильности $\mathrm{Eu}^{2+}$ (рис. 6, слой 25-4). В спектрах РЛ кварц-халцедоновых образований участка Терсюк восстановительная обстановка нашла отражение в абсолютном преобладании центров свечения, связанных с вакансией кислорода.

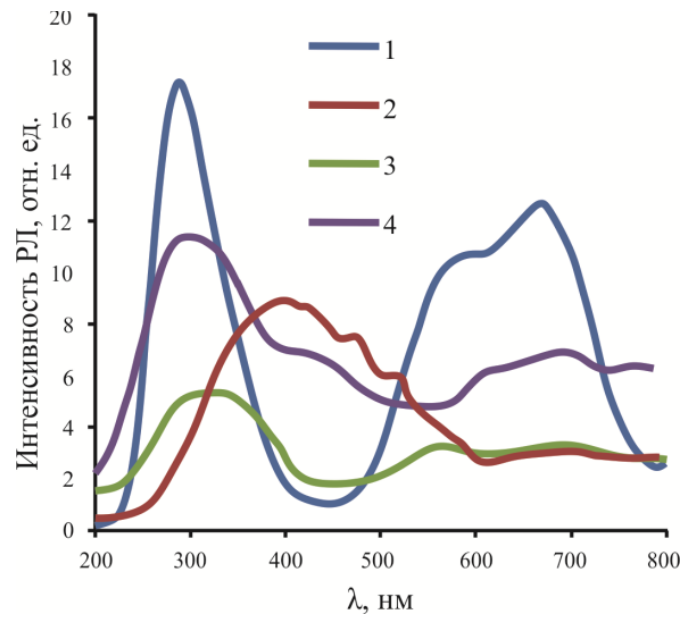

Pис. 3. Спектры РЛ квари-халиедоновых образований Южно-Кузбасского магматического ареала: 1 квари из агатов Терсюк (верх миндалины), 2 кристобалит с кварием из концентрическизонального агата Терсюк, 3 - халцедон из кониентрически-зонального агата Терсюк, 4 - квари c халцедоном из оникса Салтымаковского хребта

Fig. 3. XRL spectra of quartz-chalcedony formations of South Kuzbass magmatic area: 1 - quartz from Tersyuk agate (upper part of the amygdule), 2 cristobalite and quartz from Tersyuk agate, 3 chalcedony from Tersyuk agate, 4 - quartz and chalcedony from Saltymakovsky ridge onyx
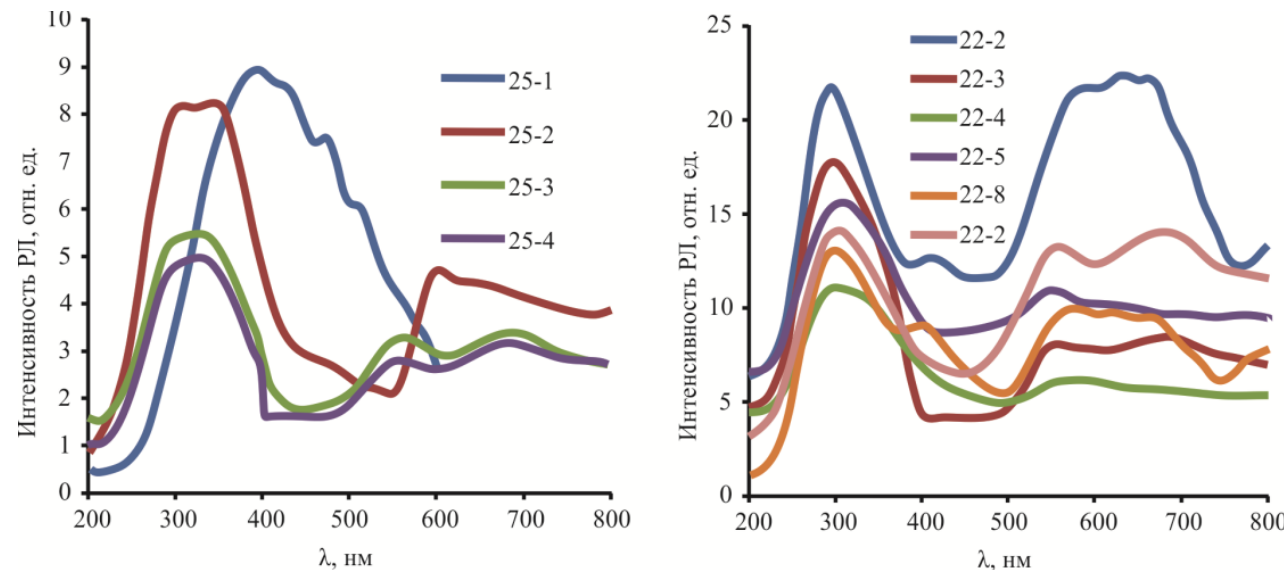

Pис. 4. Спектры РЛ отдельных слоев агата (25) и оникса (22) участка Терсюк

Fig. 4. XRL spectra of separate layers of agate (25) and onyx (22) from Tersyuk occurrence 


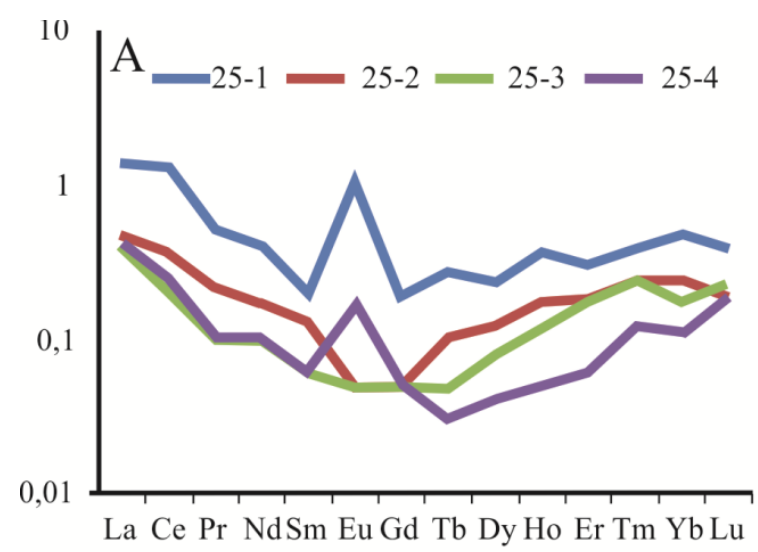

10

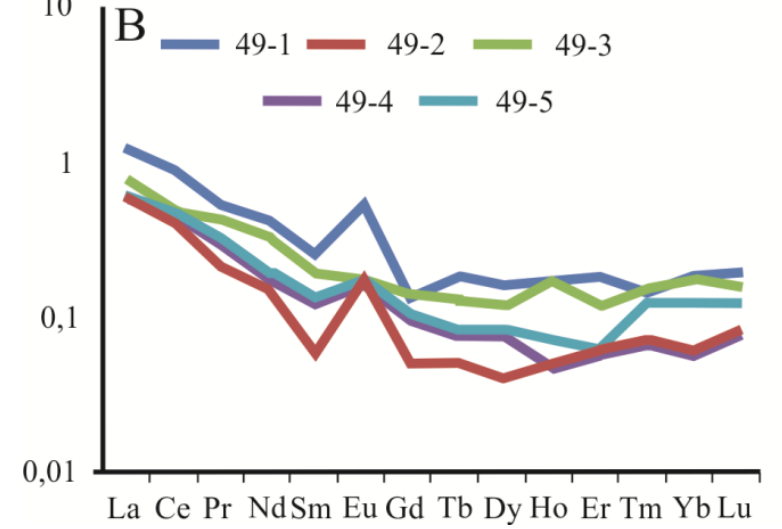

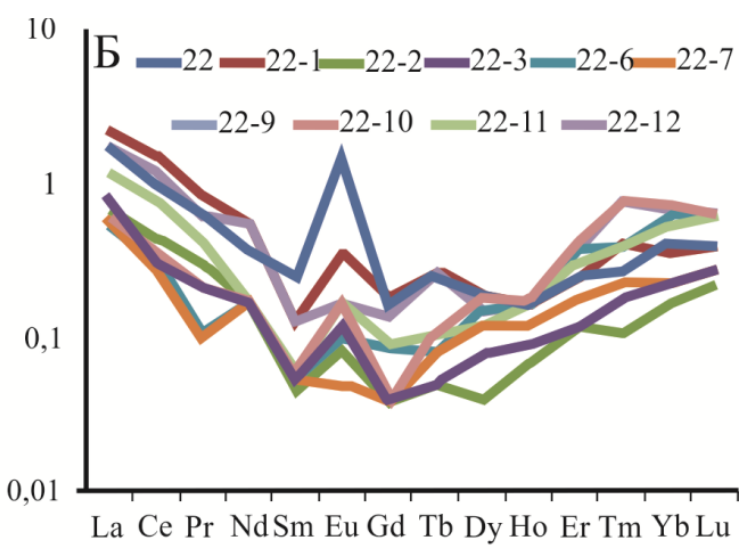

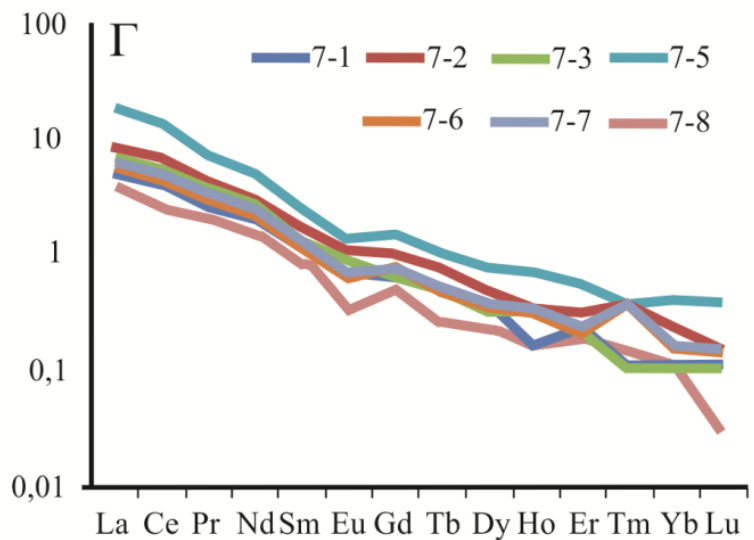

Pис. 5. Содержания редкоземельных элементов, нормированные на хондрит, для слоёв квари-халцедоновых образований проявлений участка Терсюк (А, Б), Салтымаковского хребта (B), проявления у д. Ключи (Г) [4]

Fig. 5. Chondrite-normalized contents of rare earth elements in different layers of quartz-chalcedony formations from Tersyuk occurrence $(A, B)$, Saltymakovskiy ridge occurence $(B)$, Klyuchi occurence $(\Gamma)[4]$

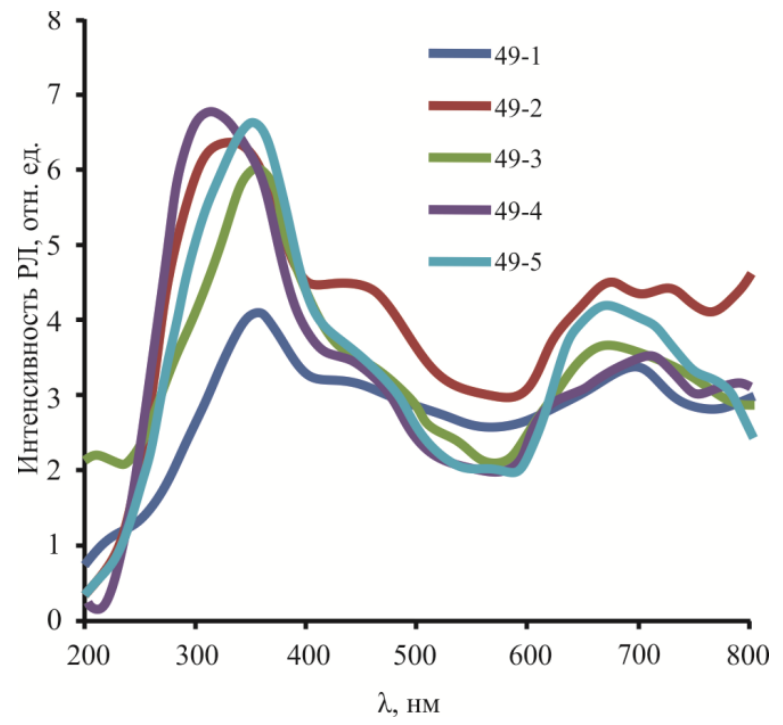

Pис. 6. Спектры рентгенолюминесиенции для отдельных слоев оникса Салтымаковского хребта

Fig. 6. XRL spectra of separate layers of Saltymakovskiy ridge onyx

Для оникса Салтымаковского хребта характерна идентичность спектров РЛ для всех исследуемых слоев, что свидетельствует о постоянстве условий минералообразования (рис. 6). Особенностью этих спектров является отсутствие свечения, связанного с вакансией кислорода (280-320, 560-580 нм), в то время как другие центры, связанные так или иначе с возбужденным кислородным состоянием, хорошо проявлены. Это междоузельный кислород (350-380 нм), дефекты матрицы $\mathrm{SiO}_{2}$ (380-400, 470-500 нм), немостиковый кислород (600-660 нм). В слоях 49-2 и 49-4 кроме указанных центров присутствуют $\mathrm{AlO}_{4}{ }^{4-} / \mathrm{Na}^{+}$ центры (330-340, 400-440 нм) и хорошо проявленное свечение $\mathrm{Fe}^{3+}$ в диапазоне 700-720 нм, что может быть связано как с усилением окислительного потенциала, так и с колебаниями щелочности, о чём свидетельствует появление щелочных компенсаторов среди центров люминесценции.

По данным геохимического изучения все слои оникса Салтымаковского хребта характеризуются положительной европиевой аномалией $\left(\mathrm{Eu} / \mathrm{Eu}^{*}=1,03-\right.$ 2,6), что, казалось бы, должно свидетельствовать в пользу повышенного восстановительного потенциала, но в третьем, четвертом и пятом слоях эта аномалия совсем слабая (на уровне 1), что может отражать влияние окислительной среды на ослабление степени проникновения европия вглубь миндалины (рис. 5 , В).

В образце 7 (д. Ключи) по геохимическим данным (рис. 5, Г) во всех слоях отмечена отрицательная европиевая аномалия $\left(\mathrm{Eu} / \mathrm{Eu}^{*}=0,3-0,8\right)$. Данный факт может быть следствием повышенного окислительного потенциала в условиях открытого доступа кислорода. Спектры РЛ также отражают влияние повышенного окислительного потенциала: во всех слоях (как в халцедоне, так и в кварце) отсутствует свече 
ние, связанное с вакансией кислорода (280-320, 560-580 нм). За свечение в видимой области спектра могут быть ответственны дефекты матрицы $\mathrm{SiO}_{2}$, междоузельный кислород, $\mathrm{SiO}_{4}{ }^{3-} / \mathrm{Na}^{+}, \mathrm{AlO}_{4}{ }^{4-} / \mathrm{Na}^{+}$,

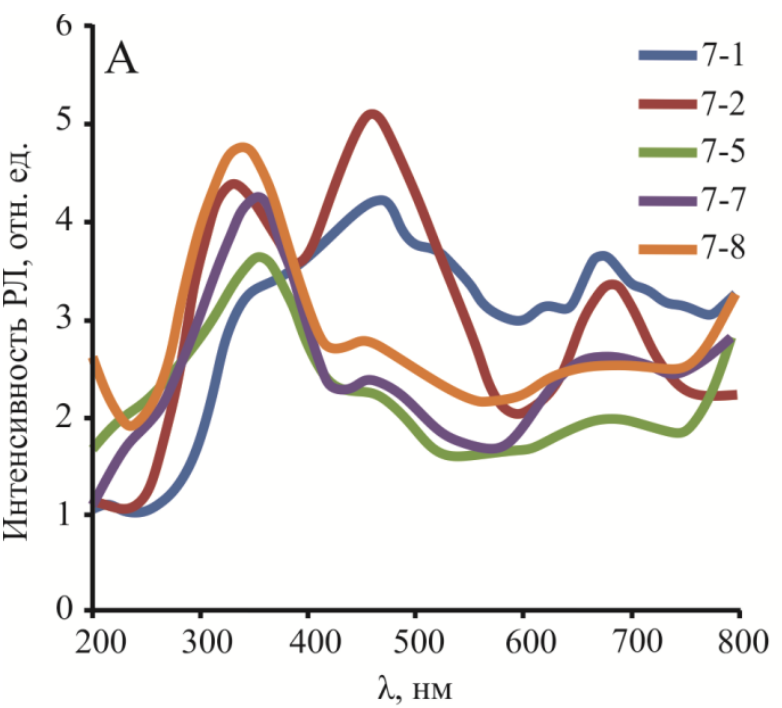

$\mathrm{AlO}_{4}{ }^{4-} / \mathrm{Li}^{+}$, в длинноволновой области - немостиковый кислород и $\mathrm{Fe}^{3+}$ (рис. 7). При этом в халцедоне примесные дефекты (свечение в диапазоне 400-600 нм) проявлены более четко.

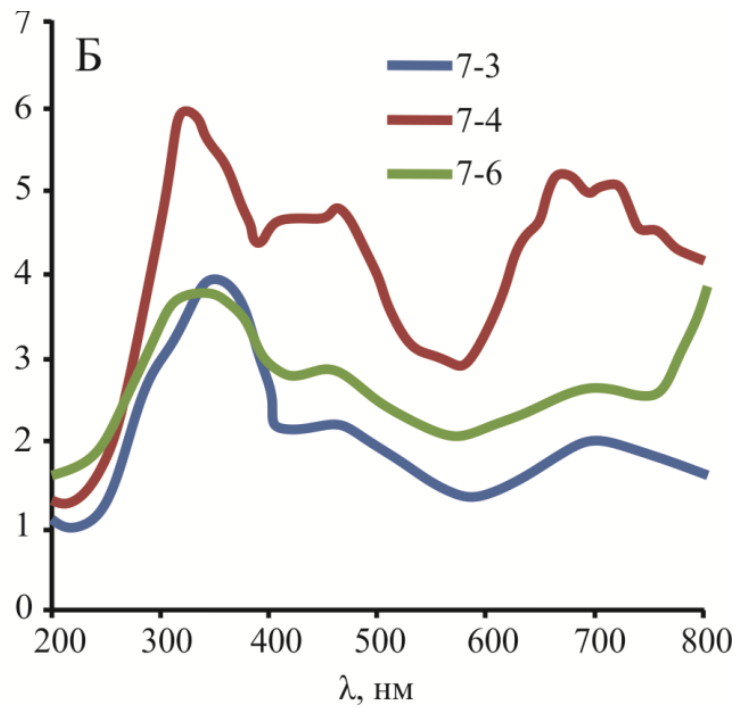

Рис. 7. Спектры рентгенолюминесценции для отдельных слоев оникса проявления у д. Ключи, сложенных халиедоном (A) и кварием (Б)

Fig. 7. XRL spectra of separate layers of Klyuchi occurrence onyx consisting of chalcedony (A) and quartz (B)

\section{Заключение}

С помощью рентгенолюминесцентного анализа получены данные о содержании собственных и примесных дефектов различной природы. Сравнение геохимических и люминесцентных данных показало зависимость люминесцентных характеристик от окислительновосстановительного потенциала. Влияние восстановительного режима в спектрах РЛ четко фиксируется по наличию полос излучения, за которые ответственны вакансии кислорода. Распределение центров РЛ в слоях агата и оникса участка Терсюк может свидетельствовать о смене окислительного потенциала (во внешней зоне) на восстановительный (во внутренних зонах), что подтверждается геохимическими данными. Для оникса Салтымаковского хребта характерна идентичность спектров РЛ для всех исследуемых слоев, что свидетельствует о постоянстве условий минералообразования. В целом сделан вывод о преобладании в миндалинах участка Терсюк восстановительной среды, а в миндали-

\section{СПИСОК ЛИТЕРАТУРЫ}

1. Годовиков А.А., Рипинен О.И., Моторин С.Г. Агаты. - М.: Недра, 1987. - 368 с

2. Шабалин Л.И. Генезис агатов, гидротермальных месторождений и гранитоидных магматических пород как результат действия СРПС (силы разуплотнения поверхностного слоя веществ). - Новосибирск: СНИИГГиМС, 2013. -269 с.

3. Текстурно-морфологические особенности кварцхалцедоновых образований в пределах проявлений ЮжноКузбасского магматического ареала (Южная Сибирь) / Е.В. Токарева, С.И. Коноваленко, Н.Н. Борозновская, Т.С. Небера // Успехи современного естествознания. - 2017. - № 7. C. 113-117.

4. Звягинцева Е.В. Геохимическая характеристика кварцхалцедоновых образований Кузбасского магматического ареала // Вестник ИГ Коми НЦ УрО РАН. - 2018. - № 4. - С. 19-25. нах проявлений Салтымаковского хребта и у д. Ключи окислительной. Наличие двух типов минерализации, отличающихся по люминесцентным свойствам минералов, коррелирующих с различными типами структурных дефектов, может быть связано с разными этапами и генерациями кварц-халцедоновых образований. Присутствие в одном образце как европиевого максимума, так и минимума с послойным их чередованием, а также смена спектрального состава излучения говорят о возможности смены окислительно-восстановительных свойств среды и стадийности процесса.

Исследования были проведены с использованием оборудования иентра коллективного пользования "Аналитический центр геохимии природных систем» Национального исследовательского Томского государственного университета в рамках государственного задания РФ. Изучение микропримесного состава проведено при поддержке Правительства Российской Федеращии в рамках проекта № 14.Y26.31.0012.

5. A unit for registration of luminescence spectra of natural objects / N.N. Boroznovskaya, V.A. Dimaki, A.V. Klimkin, A.P. Korneva, V.E. Prokopiev, V.G. Sokovikov // Proceedings of SPIE. - 2018. V. 10614. URL: https://www.researchgate.net/publication/ 324565774_A_unit_for_registration_of_luminescence_spectra_of natural_objects (дата обращения 28.08.2020).

6. Барсанов Г.П., Яковлева М.С. Минералогия поделочных и полудрагоценных разновидностей тонкозернистого кремнезема. - М.: Наука, 1984. - 144 с.

7. Hatipoğlu M., Ajò D., Sezai Kirikoğlu M. Cathodoluminescence (CL) features of the Anatolian agates, hydrothermally deposited in different volcanic hosts from Turkey // Journal of Luminescence. 2011. - V. 131. - P. 1131-1139.

8. Cathodoluminescence of quartz from sandstones: interpretation of the UV range by determination of trace element distribution and fiuid-inclusion P-T-X properties in authigenic quartz / C. Demars, 
M. Pagel, E. Deloule, P. Blanc // American Mineralogist. - 1996. V. 81. - P. 891-901.

9. Stevens-Kalceff M.A., Phillips M.R. Cathodoluminescence microcharacterization of the defect structure of quartz // Physical Review B. - 1995. - V. 52. - P. 3122-3134.

10. Thermoluminescence spectra of igneous quartz and hydrotherma vein quartz / W.J. Rink, H. Rendell, E.A. Marseglia, B.J. Luff, P.D. Townsend // Physics and Chemistry of Minerals. - 1993. V. 20. - P. 353-361.

11. Origin and geochemistry of agates in Permian volcanic rocks of the Sub-Erzgebirge basin, Saxony (Germany) / J. Götze, R. Möckel, T. Vennemann, A. Müller // Chemical Geology. 2016. - V. 428. - P. 77-91.

12. Defect structure and luminescence behaviour of agate - results of electron paramagnetic resonance (EPR) and cathodoluminescence (CL) studies / J. Götze, M. Plötze, H. Fuchs, D. Habermann // Mineralogical Magazine. - 1999. - V. 63. - P. 149-163.

13. Boroznovskaya N.N., Nebera T.S. Luminescence of rock-forming quartz of the granitoids from the Kolyvan-Tomsk folded belt in relation to facies features of massif formation // Acta Geodynamica et Geomaterialia. - 2018. - V. 15. - P. 57-66.

14. Таращан А.Н. Люминесценция минералов. - К.: Наукова думка, 1978. - 296 с

15. Люминесценция кварцевого стекла, индуцированная рентгеновским излучением / И.Н. Мисюра, С.И. Кононенко, О.В. Калантарьян, В.П. Журенко, Р.В. Скиба, С.С. Авотин, Н.Я. Рохманов // Журнал физики и инженерии поверхности. 2016. - T. 1. - № 3. - C. 282-288.
16. Magmatic and metasomatic processes during formation of the $\mathrm{Nb}$ Zr-REE deposits Khaldzan Buregte and Tsakhir (Mongolian Altai) Indications from a combined CL-SEM study / U. Kempe, J. Götze, S. Dandar, D. Habermann // Mineralogical Magazine. - 1999. V. 63. - № 2. - P. 165-177.

17. Pott G.T., McNicol B.D. Spectroscopic study of the coordination and valence of Fe and $\mathrm{Mn}$ ions in and on the surface of aluminas and silicas // Discussions of the Faraday society. - 1971. - V. 52. P. 121-131.

18. Cathodoluminescence microcharacterisation of silicon dioxide polymorphs / M.A. Stevens-Kalceff, M.R. Phillips, A.R. Moon, W. Kalceff // Cathodoluminescence in Geosciences. - 2000. P. 193-224. URL: https://link.springer.com/chapter/10.1007/9783-662-04086-7_8 (дата обращения 28.08.2020).

19. Investigation of the thermal microstructural effects of $\mathrm{CO} 2$ laser engraving on agate via X-ray microtomography / M.K. Cidade, F.L. Palombini, L. Cunha Duarte, S. Paciornik // Optics and Laser Technology. - 2018. - V. 104. - P. 56-64.

20. Luminescence behavior and Raman characterization of dendritic agate in the Dereyalak village (Eskișehir), Turkey / L. Parali, J. Garcia Guinea, R. Kibar, A. Cetin, N. Can // Journal of Luminescence. - 2011. - V. 131. - P. 2317-2324.

21. Möller P. Rare earth element and yttrium fractionation caused by fluid migration // Journal of the Czech Geological Society. 1997. - V. 42. - № 3. - P. 43.

Поступила 04.09.2020 г.

\section{Информация об авторах}

Борозновская Н.H., кандидат геолого-минералогических наук, старший научный сотрудник центра коллективного пользования «Аналитический центр геохимии природных систем», Томский государственный университет.

Звягинцева E.B., аспирант кафедры минералогии и геохимии геолого-географического факультета, Томский государственный университет.

Корнева А.П., инженер-исследователь центра коллективного пользования «Аналитический центр геохимии природных систем», Томский государственный университет.

Небера T.C., кандидат геолого-минералогических наук, ведущий инженер кафедры минералогии и геохимии геолого-географического факультета, Томский государственный университет. 
UDC 553.87

\title{
LUMINESCENCE OF QUARTZ-CHALCEDONY FORMATIONS OF KUZBASS AND ITS RELATION TO GEOCHEMICAL CHARACTERISTICS OF AGATES
}

\author{
Nina N. Boroznovskaya ${ }^{1}$, \\ boroznovskaya@mail.ru
}

\section{Elizaveta V. Zvyagintseva1, zmei7772006@mail.ru}

\author{
Alexandra P. Korneva ${ }^{1}$, \\ korneva@mail.tsu.ru

\section{Tatiana S. Nebera ${ }^{1}$,} \\ tsnebera@mail.ru \\ 1 Tomsk State University, \\ 36, Lenin avenue, Tomsk, 634050, Russia.
}

The relevance of the research is caused by quartz-chalcedony formations of Kuzbass being a potential gem and ornamental stones and by existing uncertainties related to agates formation issues. At the same time Kuzbass agates require more profound mineralogical study. The aim of the research is to study such luminescence features of quartz-chalcedony formations of South Kuzbass magmatic area as spectral composition and its variations in different zones and layers of studied samples; variations of certain luminescence centers behavior; the way geochemical features influence luminescence spectra of studied minerals.

The objects of the research are quartz-chalcedony formations of South Kuzbass magmatic area including placer-type Klyuchi occurrence (Krapivinsk rayon), agate-containing amygdaloidal basalts of Tersyuk occurrence (Novokuznetsk rayon), agate-containing amygdaloidal basalts of Saltymakovskiy ridge occurences (Krapivinsk rayon) in Kemerovo region.

The methods of the research are $X$-ray diffraction analysis, $X$-ray luminescence analysis and inductively coupled plasma mass spectrometry. Results. Mineralogical composition was studied with use of X-ray diffraction analysis. The most abundant minerals are quartz and chalcedony (with quartz prevailing). Chalcedony highest content was observed in amygdules with concentrical zoning. Among other minerals there are cristobalite, dolomite, calcite, zeolites. Contents of intrinsic and extrinsic defects of different nature taking places in minerals structure were studied by means of $X$-ray luminescence analysis. Luminescence centers distribution in different layers of Tersyuk agates may be an evidence that oxidative conditions in outer zone changed to reductive conditions in inner zones. This change was also confirmed by geochemical study results. X-ray luminescence spectra of different layers of Saltymakovskiy ridge onyxes are identic to each other. This means that mineral formation conditions were rather stable. It was concluded that there was oxidative environment in amygdules of Saltymakovskiy ridge and Klyuchi occurrences while in amygdules of Tersyuk occurrence there was reductive environment mostly.

\section{Key words:}

Quartz, chalcedony, agate, onyx, South Kuzbass magmatic area, luminescence, structure defects.

The investigations were carried out with use of equipment of collective use center "Analytical center of geochemistry of natural systems» of National research Tomsk State University. Elemental composition study was supported by the Government of the Russian Federation (project no. 14.Y26.31.0012).

\section{REFERENCES}

1. Godovikov A.A., Ripinen O.I., Motorin S.G. Agaty [Agates]. Moscow, Nedra Publ., 1987. 368 p.

2. Shabalin L.I. Genezis agatov, gidrotermalnykh mestorozhdeniy $i$ granitoidnykh magmaticheskikh porod kak rezultat deystvia SRPS (sily razuplotneniya poverkhnostnogo sloya veshchestv) [Genesis of agates, hydrothermal deposits and granitoid magmatic rocks as a result of action of the FDSL (force of decondensation of the surface layer of substances)]. Novosibirsk, SRIGGMR Publ., 2013. $269 \mathrm{p}$.

3. Tokareva E.V., Konovalenko S.I., Boroznovskaya N.N., Nebera T.S. Textural and morphological features of quartzchalcedony matter from South Kuzbass igneous areal occurences (Southern Siberia). Advances in current natural sciences, 2017, no. 7, pp. 113-117. In Rus.

4. Zvyagintseva E.V. Geochemical characteristics of quartzchalcedony formations of Kuzbass magmatic area. Vestnik of the Institute of Geology of the Komi Science Centre UB RAS, 2018, no. 4, pp. 19-25. In Rus.

5. Boroznovskaya N.N., Dimaki V.A., Klimkin A.V., Korneva A.P., Prokopiev V.E., Sokovikov V.G. A unit for registration of luminescence spectra of natural objects. Proceedings of SPIE, 2018, vol. 10614. Available at: https://www.researchgate.net/publication/

324565774_A_unit_for_registration_of_luminescence_spectra_of natural_objects (accessed 28 August 2020).

6. Barsanov G.P., Yakovleva M.S. Mineralogiya podelochnykh $i$ poludragotsennykh raznovidnostey tonkozernistogo kremnezema [Mineralogy of ornamental and semiprecious kinds of fine-grained silica]. Moscow, Nauka Publ., 1984. 144 p.

7. Hatipoğlu M., Ajò D., Sezai Kirikoğlu M. Cathodoluminescence (CL) features of the Anatolian agates, hydrothermally deposited in different volcanic hosts from Turkey. Journal of Luminescence, 2011, vol. 131, pp. 1131-1139.

8. Demars C., Pagel M., Deloule E., Blanc P. Cathodoluminescence of quartz from sandstones: interpretation of the UV range by determination of trace element distribution and fiuid-inclusion PT-X properties in authigenic quartz. American Mineralogist, 1996, vol. 81, pp. 891-901.

Stevens-Kalceff M.A., Phillips M.R. Cathodoluminescence microcharacterization of the defect structure of quartz. Physical Review B, 1995, vol. 52, pp. 3122-3134. 
9. Rink W.J., Rendell H., Marseglia E.A., Luff B.J., Townsend P.D. Thermoluminescence spectra of igneous quartz and hydrothermal vein quartz. Physics and Chemistry of Minerals, 1993, vol. 20, pp. 353-361.

10. Götze J., Möckel R., Vennemann T., Müller A. Origin and geochemistry of agates in Permian volcanic rocks of the SubErzgebirge basin, Saxony (Germany). Chemical Geology, 2016, vol. 428, pp. 77-91.

11. Götze J., Plötze M., Fuchs H., Habermann D. Defect structure and luminescence behaviour of agate - results of electron paramagnetic resonance (EPR) and cathodoluminescence (CL) studies. Mineralogical Magazine, 1999, vol. 63, pp. 149-163.

12. Boroznovskaya N.N., Nebera T.S. Luminescence of rock-forming quartz of the granitoids from the Kolyvan-Tomsk folded belt in relation to facies features of massif formation. Acta Geodynamica et Geomaterialia, 2018, vol. 15, pp. 57-66.

13. Taraschan A. N. Lyuminestsentsia mineralov [Luminescence of minerals]. Kiev, Naukova dumka Publ., 1978. 296 p.

14. Mysiura I.N., Kononenko S.I., Kalantaryan O.V., Zhurenko V.P., Skiba R.V., Avotin S.S., Rokhmanov N.Y. Luminescence of quartz glass induced by X-rays. Journal of Surface Physics and Engineering, 2016, vol. 1, no. 3, pp. 282-288. In Rus.

15. Kempe U., Götze J., Dandar S., Habermann D. Magmatic and metasomatic processes during formation of the Nb-Zr-REE deposits Khaldzan Buregte and Tsakhir (Mongolian Altai):
Indications from a combined CL-SEM study. Mineralogical Magazine, 1999, vol. 63, no. 2, pp. 165-177.

16. Pott G.T., McNicol B.D. Spectroscopic study of the coordination and valence of $\mathrm{Fe}$ and $\mathrm{Mn}$ ions in and on the surface of aluminas and silicas. Discussions of the Faraday society, 1971, vol. 52, pp. 121-131.

17. Stevens-Kalceff M.A., Phillips M.R., Moon A.R., Kalceff W. Cathodoluminescence microcharacterisation of silicon dioxide polymorphs. Cathodoluminescence in Geosciences, 2000, pp. 193224. Available at: https://link.springer.com/chapter/10.1007/9783-662-04086-7_8 (accessed 28 August 2020).

18. Cidade M.K., Palombini F.L., Cunha Duarte L., Paciornik S. Investigation of the thermal microstructural effects of $\mathrm{CO}_{2}$ laser engraving on agate via X-ray microtomography. Optics and Laser Technology, 2018, vol. 104, pp. 56-64.

19. Parali L., Garcia Guinea J., Kibar R., Cetin A., Can N. Luminescence behavior and Raman characterization of dendritic agate in the Dereyalak village (Eskișehir), Turkey. Journal of Luminescence, 2011, vol. 131, pp. 2317-2324.

20. Möller P. Rare earth element and yttrium fractionation caused by fluid migration. Journal of the Czech Geological Society, 1997, vol. 42 , no. 3, p. 43.

Received: 4 September 2020.

Information about the authors

Nina N. Boroznovskaya, Cand. Sc., senior researcher, Tomsk State University.

Elizaveta V. Zvyagintseva, $\mathrm{PhD}$ student, Tomsk State University.

Alexandra P. Korneva, research engineer, Tomsk State University.

Tatiana S. Nebera, Cand. Sc., lead engineer, Tomsk State University. 